\title{
O RACISMO COMO UMA “IDENTIDADE SOCIAL VIRTUAL"
}

\author{
EL RACISMO COMO UNA "IDENTIDAD SOCIAL VIRTUAL"
}

RACISM AS A "VIRTUAL SOCIAL IDENTITY"

Vanessa Florêncio de OLIVEIRA ${ }^{1}$

RESUMO: O presente trabalho pretende, a partir de leituras de autores como Thomas E. Skidmore, Kabengele Munanga, Mariza Corrêa, Amanda Braga e outros, contextualizar o período histórico no qual as teorias racialistas se desenvolveram, e as implicações dessas teorias sobre a população negra. Desse modo, o trabalho pretende analisar, através do conceito de estigma do sociólogo norte americano Erving Goffman, como as teorias racialistas desenvolvidas durante a segunda metade do século XIX, colaboraram para a estigmatização corporal, moral e tribal das pessoas negras, causando o que Goffman vai chamar de "identidade social virtual" em detrimento da "identidade social real.

PALAVRAS-CHAVE: Estigma. Identidade social real. Identidade social virtual. Racismo.

RESUMEN: El presente trabajo pretende, a partir de lecturas de autores como Thomas E. Y en el contexto histórico, donde las teorías racialistas se desarrollaron, y las implicaciones de esas teorías sobre la población negra. De este modo, el trabajo pretende analizar a través del concepto de estigma del sociólogo norteamericano Erving Goffman como las teorías racialistas desarrolladas durante la segunda mitad del siglo XIX, colaboraron para la estigmatización corporal, moral y tribal de las personas negras, causando lo que Goffman va a llamar de "identidad social virtual" en detrimento de la "identidad social real.

PALABRAS CLAVE: Estigma. Identidad social real. Identidad social virtual. Racismo.

ABSTRACT: The present work intends from readings by authors like Thomas E. Skidmore, Kabengele Munanga, Mariza Corrêa, Amanda Braga and others, to contextualize the historical period where racialist theories developed, and the implications of these theories on the black population. Thus, the work intends to analyze through the concept of stigma of the American sociologist Erving Goffman as the racialist theories developed during the second half of the nineteenth century, collaborated for the corporal, moral and tribal stigmatization of the black people, causing what Goffman will call of "virtual social identity" to the detriment of "real social identity.

KEYWORDS: Stigma. Real social identity. Virtual social identity. Racism.

${ }^{1}$ Universidade Estadual Paulista (UNESP), Araraquara - SP - Brasil. Mestranda pelo Programa de Pós-Graduação em Ciências Sociais. ORCID: <https://orcid.org/0000-0002-6063-2582>. E-mail: vanessafoliver@ hotmail.com 


\section{Contextualização}

Desde a colonização e o advento da escravização de Africanos nas Américas tanto os traços físicos, quanto os culturais desses povos, vem sendo inferiorizados em relação ao do homem branco/europeu. No livro História da Beleza Negra no Brasil, lançado em 2015, a linguista Amanda Braga nos apresenta uma análise do discurso sobre a beleza negra, encontrados na passagem de três séculos; XVIII, XIX, XX, quando a visão sobre o negro passou (claro que não totalmente) de uma visão animalesca para uma visão moral. A partir da abolição, jornais, associações afro-brasileiras, impulsionados a mudar a imagem negativamente construída sobre o negro, estavam preocupados nas palavras da autora em "reeducar a raça", subtrair-lhe os estereótipos consagrados ao negro pelos séculos anteriores.

Mesmo partindo do pressuposto de que a negativação do corpo negro tem início com o sistema escravocrata, o foco está na segunda metade do século XIX e o início do século XX. É, pois, nesse momento que as teorias racialistas importadas da Europa as quais davam base para o discurso científico sobre a inferiorização do negro desenvolvem estigmas que desvalorizam esses sujeitos em sua totalidade.

Dessa forma, o conceito de estigma do sociólogo norte americano Erving Goffman se faz importante, para compreender como a estética ${ }^{2}$ negra abrange as três dimensões de estigma (corporal, moral e tribal) no imaginário da sociedade brasileira. Contribuindo para o que o autor chamou de identidade social virtual em contraposição a identidade social real ${ }^{3}$.

A partir da segunda metade do século XIX as teorias racialistas importadas da Europa, como as de Gobineau sobre degenerescência dos mestiços, depois as que pregavam o darwinismo social e tantas outras começaram a aparecer em textos como os de Sílvio Romero, famoso crítico literário da época. Segundo o historiador norte-americano Thomas E. Skidmore, o clima tinha forte influência sobre a população, essencialmente a mestiça.

Silvio Romero não duvidava que o habitat brasileiro fosse seriamente debilitante. O calor opressivo e a seca periódica contribuíram para tornar o brasileiro "indiferente e apático." Citou em tom aprovador, um manual de higiene que listava as supostas consequências físicas da vida nos trópicos sangue langoroso, digestão lenta, pele demasiado sensível (SKIDMORE, 2009, p.75).

Os estigmas que são produzidos sobre o negro nos discursos como nos de Sílvio Romero, ainda não davam conta de uma teoria científica, embora aquele autor tenha sido um

${ }^{2} \mathrm{O}$ nariz, a boca, a cor da pele e o tipo de cabelo compõem essa estética (GOMES, 2008).

${ }^{3}$ Voltarei a falar de identidade social real e identidade social virtual ao longo do texto. 
grande impulsionador para que o Brasil começasse a produzir uma ciência própria. No prefácio dos Africanos no Brasil, Romero aponta a necessidade de estudar a religião e as línguas africanas, dizendo que era uma vergonha para a ciência do Brasil, que tinha a África em sua cozinha, nunca ter produzido nada nesse sentido. Dessa forma, Romero insistia: “o negro não é só uma máquina econômica; ele é antes de tudo, e malgrado a sua ignorância, um objeto de ciência."

No entanto, os estigmas sobre o negro só começaram a ter cunho 'científico' e permear as poucas universidades brasileiras, com as pesquisas desenvolvidas pelo médico maranhense Nina Rodrigues.

O primeiro estudo etnográfico responsável de um brasileiro sobre os afrobrasileiros não veio dos museus, mas sim de um professor de medicina da prestigiada faculdade da Bahia. No começo da década de 1890, Nina Rodrigues, um jovem médico mulato, tornou-se catedrático daquela escola (SKIDMORE, 2012, p. 102).

Esse trecho do livro Preto no Branco nos traz uma data importante “1890”, período em que o Brasil passava por grandes transformações políticas, principalmente decorrentes da abolição e da proclamação da república. Nesse contexto, preocupados com o destino da nação, uma questão se colocava para Nina Rodrigues e tantos outros intelectuais de sua época era resolver o problema do Brasil mestiço. Para Nina Rodrigues, o problema que o Brasil teria que enfrentar tinha a ver a incapacidade do negro em construir uma civilização, em função do seu atraso biológico e cultural.

$\mathrm{Na}$ análise do antropólogo congolês e ex-professor da Universidade de São Paulo Kabengele Munanga: "toda a preocupação da elite, apoiada nas teorias raciais da época, diz respeito à influência negativa que poderia resultar da herança inferior do negro nesse processo de formação da identidade étnica brasileira" (1999, p. 51).

As teorias que justificavam a inferioridade do negro pó meio de um discurso que se dizia científico coincidiram (não por acaso) com o momento em que o país passava por grandes transformações, não só políticas, mas sociais e econômicas, tendo em vista que, naquele período, o país começava uma industrialização tardia.

Alijada do mercado de trabalho da ainda nascente indústria, vivia de biscates ou de empregos eventuais e temporários, morava em cortiços ou porões e sofria um quadro deprimente em matéria de condições de saúde (NASCIMENTO 2003, p. 231 apud BRAGA 2015, p. 107).

Nesse momento, as três dimensões de estigmas (corporal, moral e tribal) estavam fortemente presentes na sociedade. Todos esses estigmas pareciam se confirmar diante do 
quadro em que os negros se encontravam, perambulando pelas ruas sem emprego fixo, vivendo de "bicos", bêbados e doentes.

Para a antropóloga e ex-professora da Universidade Estadual de Campinas - UNICAMP, muitos clássicos da literatura nacional do século XIX, são fontes de registro importantes para a compreensão das relações raciais nesse contexto. Assim, uma boa parte da literatura da época, em destaque a de Aluísio de Azevedo e Euclides da Cunha, mesmo não sendo textos científicos, são capazes de nos aproximar do contexto da época, além de nos revelar os estigmas sofridos pela população negra nesse período.

O preconceito racial denunciado por Aluísio de Azevedo, o branqueamento como solução proposta por Sílvio Romero, a multiplicidade cultural, talvez malgrado sua vontade, reconhecida por Nina Rodrigues e a resistência do homem do sertão louvada por Euclides da cunha ocuparam e continuam a ocupar nossos esforços de pesquisa e as páginas dos jornais todos os dias (CORRÊA, 2013, p. 35).

Enquanto alguns intelectuais revelavam o total abandono em que a população menos favorecida sofria, por conta do poder público, outros preferiam acreditar que o problema era realmente a "mistura das raças", fazendo com que o negro continuasse a viver à margem da sociedade, sendo cada vez mais estigmatizado.

\section{A força do estigma sobre o negro}

Para o sociólogo norte americano Erving Goffman o estigma é um processo dinâmico que se desenvolve através de forças sociais e políticas. Tendo isso em vista, se faz importante o entendimento dos processos sociais e institucionais que ainda colaboram, para a perpetuação da imagem negativa sobre a população negra do país. Assim, foi durante todo o processo de colonização e escravização de africanos que a população negra e indígena começou a sofrer um processo intenso de estigmatização o qual atingiu seu ápice com as teorias racialistas disseminadas durante o final do século XIX, período em que o Estado começava a promover, uma forte política higienista. Nesse tocante, o Estado - bem como outras forças sociais agindo dessa forma - desenvolvia subjetividades que associavam o negro ao que era patológico na sociedade, ainda nas palavras de Rodrigues em o problema brasileiro.

O cenário de pobreza e miséria sob o qual vivia a população negra parecia ser a justificativa que dava conta de todos os entraves econômicos, sociais e políticos nos quais se encontrava o Brasil. 
Se durante a colonização, a animalização das pessoas negras servia como uma forma de justificar o regime escravocrata, no século XIX ela se tornou uma espécie de atração para os olhos dos curiosos, além de continuar a promover a manutenção da subalternidade das pessoas negras, através de teorias eugenistas, pautadas sobre uma suposta ciência.

Durante todo o século XIX, assistiu-se a exibição de africanos em feiras, teatros, circos e exposições. Ao lado de animais, ao mesmo tempo em que se expunham para deleite dos europeus, foram observados e estudados como elementos capazes de confirmar teorias médicas eugenistas, que versavam acerca da superioridade da raça branca (BRAGA, 2015, p. 41).

É no século XIX que esses traços genéticos, como cor da pele, formato do crânio, foram relacionados às características psicológicas desses indivíduos. Coutrine (1998) “dirá que esse é o momento em que os sinais do corpo serão sinais de uma identidade psicológica, permitindo, assim que personalidades fossem decifradas a partir dos indícios oferecidos pelo corpo" (apud BRAGA, 2015, p. 42).

Fazendo com que, a estética do negro começasse a comportar tudo que não era "normal", correto, ético, ou seja, ser negro era não fazer parte da moral e dos bons costumes, haja vista que, eram os brancos que representavam essa moral. Tudo isso possibilitou que as pessoas criassem sobre o negro uma "identidade social virtual" em detrimento de uma "identidade social real."

Para Goffman, cada sociedade determina através de uma organização própria as características que seus componentes devem possuir para serem considerados "normais", ou aptos a fazerem parte dessa sociedade. Segundo o sociólogo, isso também ocorreria com relação aos ambientes sociais, uma vez que já estaria pré-determinado por essa sociedade, quem encontramos em determinados ambientes. Ou seja, "baseando-nos nessas preconcepções, nós as transformamos em expectativas normativas, em exigências apresentadas de modo rigoroso" (GOFFMAN, 2004, p. 5).

Dessa forma, Goffman desenvolve dois conceitos: "identidade social real" e a “identidade social virtual”. O primeiro seria o que o indivíduo realmente é. O segundo seria o que outros indivíduos acreditam que ele seja baseado em concepções já pré-estabelecidas e normatizadas pela sociedade em que vivem.

Enquanto o estranho está à nossa frente, podem surgir evidências de que ele tem um atributo que o torna diferente de outros que se encontram numa categoria em que pudesse ser - incluído, sendo, até, de uma espécie menos desejável - num caso extremo, uma pessoa completamente má, perigosa ou fraca. Assim, deixamos de considerá-lo criatura comum e total, reduzindo-o a uma pessoa estragada e diminuída. Tal característica é um estigma, 
especialmente quando o seu efeito de descrédito é muito grande - algumas vezes ele também é considerado um defeito, uma fraqueza, uma desvantagem - e constitui uma discrepância específica entre a identidade social virtual e a identidade social real (GOFFMAN, 2004, p. 6).

Tendo isso em vista, o racismo seria um tipo de identidade social virtual desenvolvida sobre o negro, através de um longo processo histórico de depreciação tanto de seus traços físicos, quanto da sua moral e pertencimento étnico. O racismo comporta estigmas sobre as pessoas negras, o qual torna impossível visualizar a identidade social real daquela pessoa, em outras palavras, quem ela realmente é. Assim, criamos concepções errôneas sobre a sua personalidade baseados muitas vezes em sua aparência física.

No final do século XIX, começo do século XX, o Estado contribuiu para criar um espaço que repelia cada vez mais a presença do negro. As políticas de imigração pareciam atestar as teorias que diziam que a solução para o Brasil era investir num forte branqueamento da população. Assim, o branco/europeu se tornava, evidentemente, o padrão de beleza e moral a ser alcançado.

Isso implicou, não apenas, uma identidade social virtual de um outro sobre o negro, mas uma identidade social virtual do negro, sobre ele mesmo.

\begin{abstract}
O indivíduo estigmatizado tende a ter as mesmas crenças sobre identidade que nós temos; isso é um fato central. Seus sentimentos mais profundos sobre o que ele é podem confundir a sua sensação de ser uma "pessoa normal", um ser humano como qualquer outro, uma criatura, portanto, que merece um destino agradável e uma oportunidade legítima (GOFFMAN, 2004, p.9).
\end{abstract}

No prefácio do livro Tornar-se Negro ou As Vicissitudes da Identidade do Negro Brasileiro em Ascensão social, da psicóloga lacaniana Neusa de Sousa Santos, o também psicanalista Jurandir Freire Costa evidencia as propostas da autora para uma nova psicanálise, que consiga dar suporte aos problemas psicológicos causados às pessoas negras pelo racismo. Desse modo, identifica os processos contínuos de violência racial pelos quais os negros passam ao longo de suas vidas, até chegarem ao ponto de "formular para si um projeto identificatório incompatível com as propriedades biológicas do seu corpo" (COSTA, 1983, p. 3). Assim sendo, a pessoa negra que tenta se enquadrar nos padrões de beleza propostos pela branquitude desenvolve sobre si uma identidade social virtual, que manifesta, consciente ou inconscientemente, o desejo de ser aceito.

Para Goffman, o estigmatizado pode sentir uma forte vontade por aceitação, principalmente quando convive diariamente com "os normais". Nesse caso, as pessoas brancas seriam consideradas normais por representarem os padrões ideais das sociedades ocidentais. 
Por essa razão, a necessidade de ser aceito provocaria no sujeito estigmatizado a vontade de corrigir o "defeito" que o diferenciaria dos demais, no caso das sociedades, pautados pelos ideais da branquitude, a cor da pele e os traços fenotípicos negros, seria algo a ser corrigido.

A característica central da situação de vida, do indivíduo estigmatizado pode, agora, ser explicada. É uma questão do que é com frequência, embora vagamente, chamado de "aceitação". Aqueles que têm relações com ele não conseguem lhe dar o respeito e a consideração que os aspectos não contaminados de sua identidade social os haviam levado a prever e que ele havia previsto receber; ele faz eco a essa negativa descobrindo que alguns de seus atributos a garantem. Como a pessoa estigmatizada responde a tal situação? Em alguns casos lhe seria possível tentar corrigir diretamente o que considera a base objetiva de seu defeito, tal como quando uma pessoa fisicamente deformada se submete a uma cirurgia plástica, uma pessoa cega a um tratamento ocular, um analfabeto corrige sua educação e um homossexual faz psicoterapia (GOFFMAN, 2004, p. 11).

Segundo Goffman, mesmo o indivíduo conseguindo corrigir o que entende que seja um defeito, ele não será tratado como um normal. Segundo o sociólogo, o que vai ocorrer é uma "transformação do ego: alguém que tinha um defeito particular se transforma em alguém que tem provas de tê-lo corrigido."

No Brasil o preconceito racial é medido principalmente pelos seus traços fenotípicos, isto é, o corpo e o cabelo são marcadores importantes da negritude do sujeito. Desse modo, no afã de ser aceito pelos brancos, o sujeito negro acaba buscando formas de modificar a sua aparência estética.

Falamos de um sonho que condensa a busca por um status, bem como a busca por uma aceitação/inserção social através da estética, ainda que isso lhe custe uma profunda manipulação de seu corpo. Apostar num padrão de beleza genuinamente negro não representaria qualquer alcance. Nas tramas da história, era a estética branca que prevalecia enquanto modelo a ser seguido (BRAGA, 2015, p. 105).

Nesse trecho, podemos perceber o quanto a aparência, a presença da estética negra torna-se um fator preponderante do racismo à brasileira ${ }^{4}$."Em vez de um preconceito de origem (qualquer quantidade de sangue negro fazia um homem negro), os brasileiros tinham um preconceito de cor (uma pessoa é branca ou negra dependendo de sua aparência” (VIOTTI, 1998, p.371).

Com isso, a aparência das pessoas negras marca esses sujeitos como estigmatizados, desenvolvendo sobre eles uma identidade social virtual. Isto é, esses sujeitos não são percebidos

${ }^{4}$ Edward Telles, no livro Racismo à Brasileira, destaca que o racismo no Brasil está muito ligado a aparência da pessoa negra, enquanto nos Estados Unidos o que diz sobre sua negritude é a "gota de sangue." 
pelas suas qualidades e potencialidades individuais, mas por pré-concepções negativas sobre eles. A cor da pele, dessa maneira, seria preponderante para a criação da identidade social virtual sobre o negro, identidade essa que ainda está presente no imaginário brasileiro o qual exclui e mata a população negra.

\section{Considerações finais}

O que podemos concluir por este trabalho é que o processo de estigmatização das pessoas negras teve início na colonização. No entanto, no final do século XIX, houve uma intensificação desse processo, uma vez que a inferioridade das pessoas negras era atestada por "teorias científicas". Além das teorias científicas colaborarem para a estigmatização corporal das pessoas negras, a negligência do Estado em relação a essa população contribuiu para sua estigmatização moral e tribal, dado que, naquele período, havia repressão das religiões de matrizes africanas, bem como das práticas de capoeira. Desse modo, a população negra foi marcada, no pós abolição, pelas três categorias de estigma apresentadas pelo sociólogo Erving Goffman - corporal, moral e tribal, as quais ocasionaram a criação de uma identidade social virtual sobre essa população.

Essa identidade social virtual se apresenta em nossa sociedade como o racismo, que abriga em si uma multiplicidade de pré-suposições e estigmas desenvolvidos sobre o negro, fazendo com que ele, continue a ter o destino dos que habitam o lado escuro do país. ${ }^{5}$

\section{REFERÊNCIAS}

BRAGA, Amanda. História da Beleza Negra no Brasil: discursos, corpos e práticas. São Carlos: EDUFSCar, 2015.

CORRÊA, Mariza. As Ilusões da Liberdade: a Escola Nina Rodrigues e a antropologia no Brasil. 3 ed. Rio de Janeiro: Editora FIOCRUZ, 2013.

COSTA, Emília Viotti da. Da Monarquia à República: momentos decisivos. 6 ed. São Paulo: Fundação Editora da UNESP, 1999.

GOFFMAN, Erving. Estigma: notas sobre a manipulação da identidade deteriorada. 4. ed. São Paulo: Editora LTC, 2004.

${ }^{5}$ Sobre esse assunto consultar Poema Obsceno de Ferreira Gullar. 
GOMES, Nilma Lino. Sem Perder a Raiz: Corpo e Cabelo como Símbolos da Identidade Negra. Belo Horizonte: Autêntica, 2008.

MUNANGA, Kabengele. Rediscutindo a Mestiçagem no Brasil: identidade nacional versus identidade negra. Rio de Janeiro: Editora Vozes, 1999.

RODRIGUES, Nina. Os Africanos no Brasil. 7 ed. São Paulo: Editora UNB, 1988.

SANTOS, Neusa de Souza. Tornar-se Negro. 2 ed. Rio de Janeiro: Edições Graal, 1983.

SKIDMORE, Thomas E. Preto no Branco: raça e nacionalidade no pensamento brasileiro. $1^{\circ}$ ed. São Paulo: Companhia das Letras, 2012.

TELLES, Edward. Racismo à Brasileira: uma nova perspectiva sociológica. Rio de Janeiro: Relume Dumará: Fundação Ford, 2003.

\section{Como referenciar este artigo}

OLIVEIRA, Vanessa Florêncio de. O racismo como uma "identidade social virtual". Rev. Sem Aspas, Araraquara, v. 7, n. 2, p. 283-291, jul./dez., 2018. E-ISSN: 2358-4238. DOI: 10.29373/sas.v7i2.12496

Submetido em: 15/01/2019

Aprovado em: 19/02/2019 